\title{
UPAYA PENINGKATAN DERAJAT KESEHATAN MELALUI EDUKASI DAN SCREENING PERILAKU HIDUP BERSIH DAN SEHAT DI PANTI ASUHAN
}

\author{
Nunung Rachmawati \\ Akademi Keperawatan "YKY" Yogyakarta, Indonesia \\ rachmawa84@gmail.com
}

\begin{abstract}
There are many health problems that will greatly determine the quality of children in the future. Health problems faced by children are related to clean and healthy living habits (PHBS) which have not been implemented properly, causing health problems, such as worms, diarrhea and acute respiratory tract problems (ISPA). Most of the children in the orphanage have not properly implemented the habits of hygiene and healthy living habits. To increase awareness of clean and healthy living behavior at the Wiwin Muslimah Orphanage, education is needed on the importance of PHBS and screening of clean and healthy living behaviors. Children's awareness to behave clean and healthy after education and screening increases. Children's awareness about the importance of PHBS in the orphanage can be increased with proper education and screening.

Keywords: Children, Education, Clean and Healthy Living Behavior, Screening
\end{abstract}

\begin{abstract}
Abstrak
Banyak permasalahan kesehatan yang sangat menentukan kualitas anak dikemudian hari. Masalah kesehatan yang dihadapi anak terkait dengan perilaku hidup bersih dan sehat (PHBS) yang belum diterapkan dengan baik menimbulkan permasalahan kesehatan, seperti masalah cacingan, diare dan saluran pernafasan akut (ISPA). Sebagian besar anak di panti asuhan belum menerapkan dengan baik kebiasaan perilaku hidup bersih dan sehat. Untuk meningkatkan kesadaran dan perilaku hidup bersih dan sehat di Panti Asuhan Wiwin Muslimah diperlukan adanya edukasi tentang pentingnya PHBS dan screening perilaku hidup bersih dan sehat. Kesadaran anak untuk berperilaku bersih dan sehat setelah dilakukan edukasi dan screening meningkat. Kesadaran anak tentang pentingnya PHBS di lingkungan panti asuhan dapat ditingkatkan dengan edukasi dan screening yang tepat.
\end{abstract}

Kata Kunci: Anak, Edukasi, Perilaku Hidup Bersih dan Sehat, Screening

\begin{tabular}{l|l|l} 
Submitted: $2020-09-07$ & Revised: 2020-09-13 & Accepted: 2020-09-15
\end{tabular}

\section{Pendahuluan}

Anak merupakan aset bangsa yang harus dijaga dan dirawat agar dapat memberikan kemanfaatan dalam peradaban suatu bangsa. Kualitas dari anak-anak bangsa merupakan miniatur bagi keberlangsungan bangsa itu sendiri. Anak harus dapat tumbuh dan berkembang dengan optimal agar dapat mempersiapkan dirinya dalam mengemban tanggungjawab di masa yang akan datang. Di dalam periode ini didapatkan banyak permasalahan kesehatan yang sangat menentukan kualitas anak dikemudian hari. Masalah kesehatan tersebut meliputi kesehatan umum, gangguan perkembangan, gangguan perilaku dan gangguan belajar. Permasalahan kesehatan tersebut pada umumnya akan menghambat pencapaian prestasi pada anak disekolah (Dermawan, 2012). 
Masalah kesehatan yang dihadapi anak terkait dengan perilaku hidup bersih dan sehat (PHBS) yang belum diterapkan dengan baik, sehingga menimbulkan permasalahan kesehatan, seperti masalah cacingan, diare dan saluran pernafasan akut (ISPA). Menurut data dari Departemen Kesehatan menyebutkan bahwa diantara 1000 penduduk terdapat 300 orang yang terjangkit penyakit diare sepanjang tahun dan berdasarkan Badan Kesehatan Dunia (World Health Organization/WHO) setiap tahunnya ada 100.000 anak di Indonesia meninggal akibat diare. (Depkes RI, 2007).

Pendidikan kesehatan di panti asuhan sangat efektif dilakukan karena sebagian besar waktu anak-anak berada di panti asuhan. Selain berfungsi sebagai tempat pembelajaran, panti asuhan harus menjadi suatu tempat yang dapat meningkatkan derajat kesehatan anak asuh dengan meningkatkan perilaku hidup bersih dan sehat (PHBS) serta menciptakan lingkungan yang sehat. Anak merupakan kelompok yang sangat peka untuk menerima perubahan atau pembaharuan, karena kelompok anak sedang berada dalam taraf pertumbuhan dan perkembangan. Pada taraf ini anak dalam kondisi peka terhadap stimulus sehingga mudah dibimbing, diarahkan dan ditanamkan kebiasaan-kebiasaan yang baik, termasuk kebiasaan berperilaku hidup bersih dan sehat (Notoatmodjo, 2005).

Upaya yang dapat dilakukan agar anak dapat melewati masa pertumbuhan dan perkembangannya secara optimal adalah dengan menggalakkan program Perilaku Hidup Bersih dan Sehat (Kurniawan, 2017). PHBS merupakan langkah yang harus dilakukan untuk mencapai derajat kesehatan yang optimal bagi setiap orang (Andriansyah, Rahmantari, 2013). Program PHBS telah berjalan 15 tahun tetapi belum mampu mencapai indeks ketercapaian program (Kemenkes RI, 2011). Salah satu tempat yang memiliki indeks ketercapaian program PHBS dibawah rata-rata adalah panti asuhan (Kurniawan, 2017). Salah satu panti asuhan yang menarik untuk dilihat perilaku hidup bersih dan sehatnya yaitu Panti Asuhan Yatim dan Dhuafa Wiwin Muslimah yang terletak di Jalan Veteran 128 B Warungboto, Kecamatan Umbulharjo, Daerah Istimewa Yogyakarta. Yayasan Rumah Yatim dan Dhuafa Wiwin Muslimah adalah sebuah yayasan yang bergerak di bidang sosial yang saat ini masih fokus pembinaan anak yatim dan dhuafa.

Dari hasil studi pendahuluan yang dilakukan di Panti Asuhan Yatim dan Dhuafa Wiwin Muslimah Yogyakarta diperolah data bahwa jumlah seluruh anak asuh adalah 21 anak, terdiri dari 10 anak laki-laki dan 11 anak perempuan. Jumlah pengurus panti asuhan sebanyak 7 orang. Keadaan lingkungan Panti Asuhan Yatim dan Dhuafa Wiwin Muslimah kurang bersih. Hasil wawancara terhadap salah satu pengurus panti asuhan menunjukkan bahwa sebagian besar anak masih mempunyai kebiasaan membuang sampah tidak pada tempatnya meskipun sudah ada tempat sampah di setiap kamar dan sering diingatkan oleh pengurus panti untuk membuang sampah pada tempat sampah, selain itu masih ada beberapa anak yang memiliki kutu rambut dikarenakan tidak rajin mencuci rambut sehingga dikhawatirkan dapat menyebarkan ke anak yang lainnya. Berdasarkan hasil wawancara juga didapatkan data bahwa anak panti sulit untuk disuruh mandi, cuci tangan dan membersihkan dan membereskan ruangan masing-masing. Berdasarkan hasil pengamatan kondisi rumah panti bagian belakang kurang rapi tetapi sirkulasi udara dan pencahayaan baik, kondisi air di kamar mandi dikosongkan dan lantai agak licin.

Pemahaman tentang pentingnya perilaku hidup bersih dan sehat (PHBS) kepada anak di panti asuhan sangatlah penting. Mengingat sebagian besar anak yang tinggal di panti 
BERNAS:

Jurnal Pengabdian Kepada Masyarakat
Vol.1 No. 4, October 2020, pp. 327-332

asuhan adalah anak yatim dan atau piatu, maka setiap anak dituntut untuk mandiri dan memiliki kesadaran yang tinggi tentang pentingnya hidup bersih dan sehat. Peran orang tua pengganti dalam hal ini pengurus panti juga tidak kalah penting dalam meningkatkan kesadaran anak panti. Berdasarkan permasalah di atas, perlu adanya kegiatan edukasi dan screening yang dikemas dalam pengabdian kepada masyarakat yang nantinya memberikan pengetahuan materi yang berkaitan dengan Perilaku Hidup Bersih Sehat (PHBS) melalui edukasi dan gambaran perilaku hidup bersih dan sehat anak panti melalui screening di Panti Asuhan Yatim dan Dhuafa Wiwin Muslimah Yogyakarta.

\section{Metode}

Metode yang digunakan dalam kegiatan ini adalah metode ceramah dan pemeriksaan fisik dengan menampilkan media audio visual, demonstrasi, tanya jawab serta screening kesehatan dan kebersihan diri. Kegiatan diawali dengan melakukan pemeriksaan kebersihan diri masing-masing anak panti (personal hygiene) dari mulai kepala sampai kaki yang dilanjutkan kegiatan pemberian penjelasan dan paparan tentang Perilaku Hidup Bersih dan Sehat (PHBS). Pelaksanaan kegiatan terbagi menjadi tiga tahapan yaitu perencanaan, pelaksanaan, observasi dan evaluasi pengabdian pada masyarakat (PPM).

1. Perencanaan PPM

Pada tahap perencanaan hal-hal yang dilakukan diantaranya :

a. Melakukan koordinasi dengan mitra dan survei lokasi pelaksanaan kegiatan PPM

b. Menentukan metode dan media kegiatan PPM

c. Melakukan koordinasi dan persamaan persepsi dengan mahasiswa yang dilibatkan

2. Pelaksanaan PPM

Pelaksanaan kegiatan PPM di Panti Asuhan Yatim dan Dhuafa Wiwin Muslimah Yogyakarta meliputi :

a. Pemeriksaan kebersihan diri (personal hygiene) anak panti yang meliputi kebersihan rambut, kebersihan telinga, kebersihan kuku dan kesehatan gigi.

b. Penyampaian materi tentang Perilaku Hidup Bersih dan Sehat dari dosen keperawatan

c. Demonstrasi cuci tangan dan gosok gigi yang benar oleh mahasiswa yang dilibatkan

3. Observasi dan Evaluasi PPM

Pada akhir kegiatan PPM peserta diberi kesempatan untuk mensimulasikan/ memperagakan kembali cuci tangan dan gosok gigi yang benar. Selain itu peserta juga diberikan beberapa pertanyaan untuk dijawab secara langsung. Hal ini dilakukan untuk mengetahui keberhasilan kegiatan yang telah dilakukan.

\section{Hasil dan Pembahasan}

Berdasarkan hasil pemeriksaan kebersihan dan kesehatan / screening anak asuh di Panti Asuhan Yatim dan Dhuafa Wiwin Muslimah Yogyakarta didapatkan hasil sebagai berikut : 


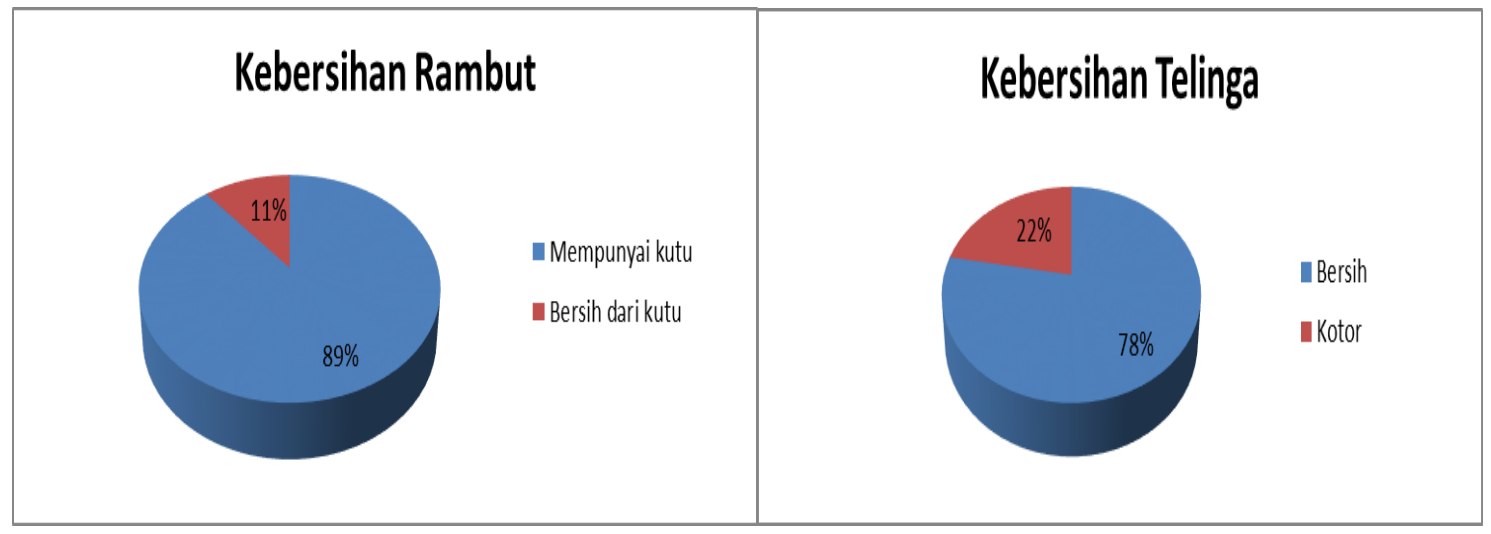

Gambar 1. Hasil Pemeriksaan Kebersihan Rambut dan Telinga Anak Panti Asuhan Yatim dan Dhuafa Wiwin Muslimah Yogyakarta

Berdasarkan gambar 1. didapatkan bahwa sebagian besar anak asuh di Panti Asuhan Yatim dan Dhuafa Wiwin Muslimah Yogyakarta mempunyai kutu rambut yaitu sebesar $89 \%$. Sedangkan sebagian besar kebersihan telinga anak asuh di Panti Asuhan Yatim dan Dhuafa Wiwin Muslimah Yogyakarta bersih yaitu sebesar 78\%.

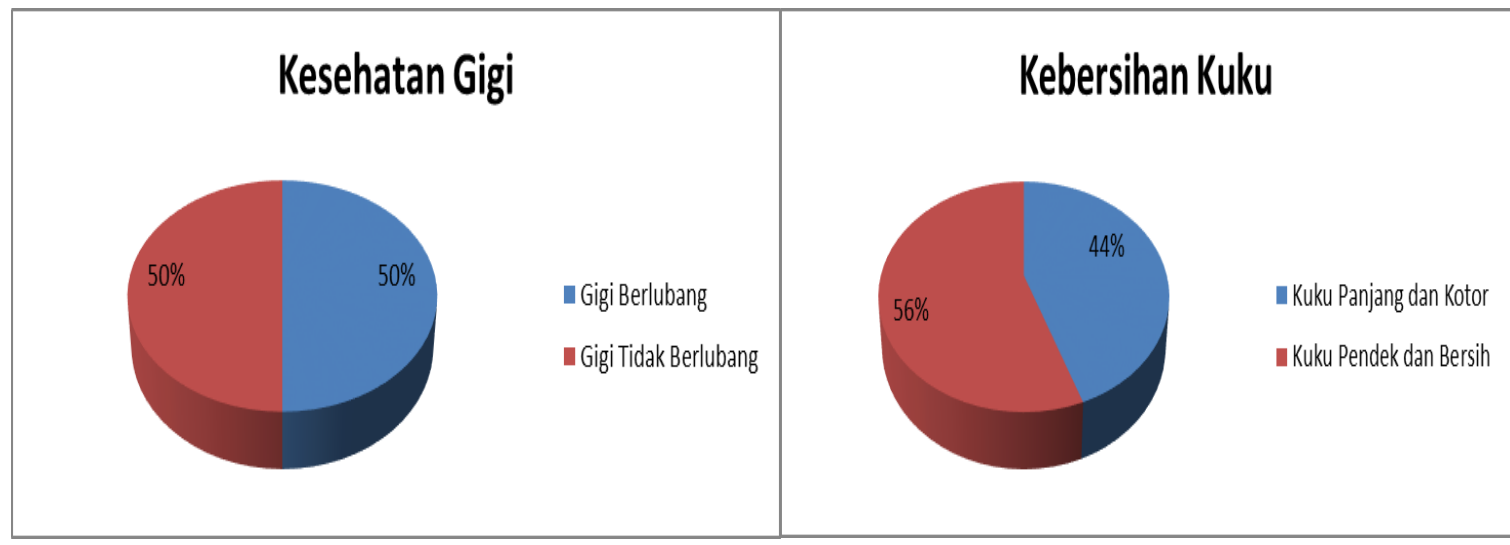

Gambar 2. Hasil Pemeriksaan Kesehatan Gigi dan Kebersihan Kuku Anak Panti Asuhan Yatim dan Dhuafa Wiwin Muslimah Yogyakarta

Berdasarkan gambar 2. didapatkan bahwa 50\% anak asuh di Panti Asuhan Yatim dan Dhuafa Wiwin Muslimah Yogyakarta mempunyai gigi yang berlubang. Sebagian besar kebersihan kuku anak asuh di Panti Asuhan Yatim dan Dhuafa Wiwin Muslimah Yogyakarta bersih dan kondisi kuku pendek yaitu sebesar $56 \%$.

Setelah dilakukan pemeriksaan kebersihan diri dilanjutkan dengan kegiatan edukasi, demonstrasi dan tanya jawab. Sebelum edukasi tentang PHBS diberikan dilakukan tanya jawab terkait PHBS, berdasarkan hasil tanya jawab didapatkan hasil bahwa semua anak asuh di Panti Asuhan Yatim dan Dhuafa Wiwin Muslimah Yogyakarta belum memahami tentang PHBS. Edukasi dimulai dengan pemaparan tentang perilaku hidup bersih dan sehat yang meliputi cuci tangan, kebersihan kuku, kebiasaan BAB dan BAK di jamban sehat, membuang sampah pada tempatnya, pemeriksaaan jentik-jentik, dan jajan makanan yang 
BERNAS:

Jurnal Pengabdian Kepada Masyarakat

Vol.1 No. 4, October 2020, pp. 327-332

sehat. Edukasi dilakukan dengan metode ceramah dengan menampilkan media audio dan visual dan demonstrasi.

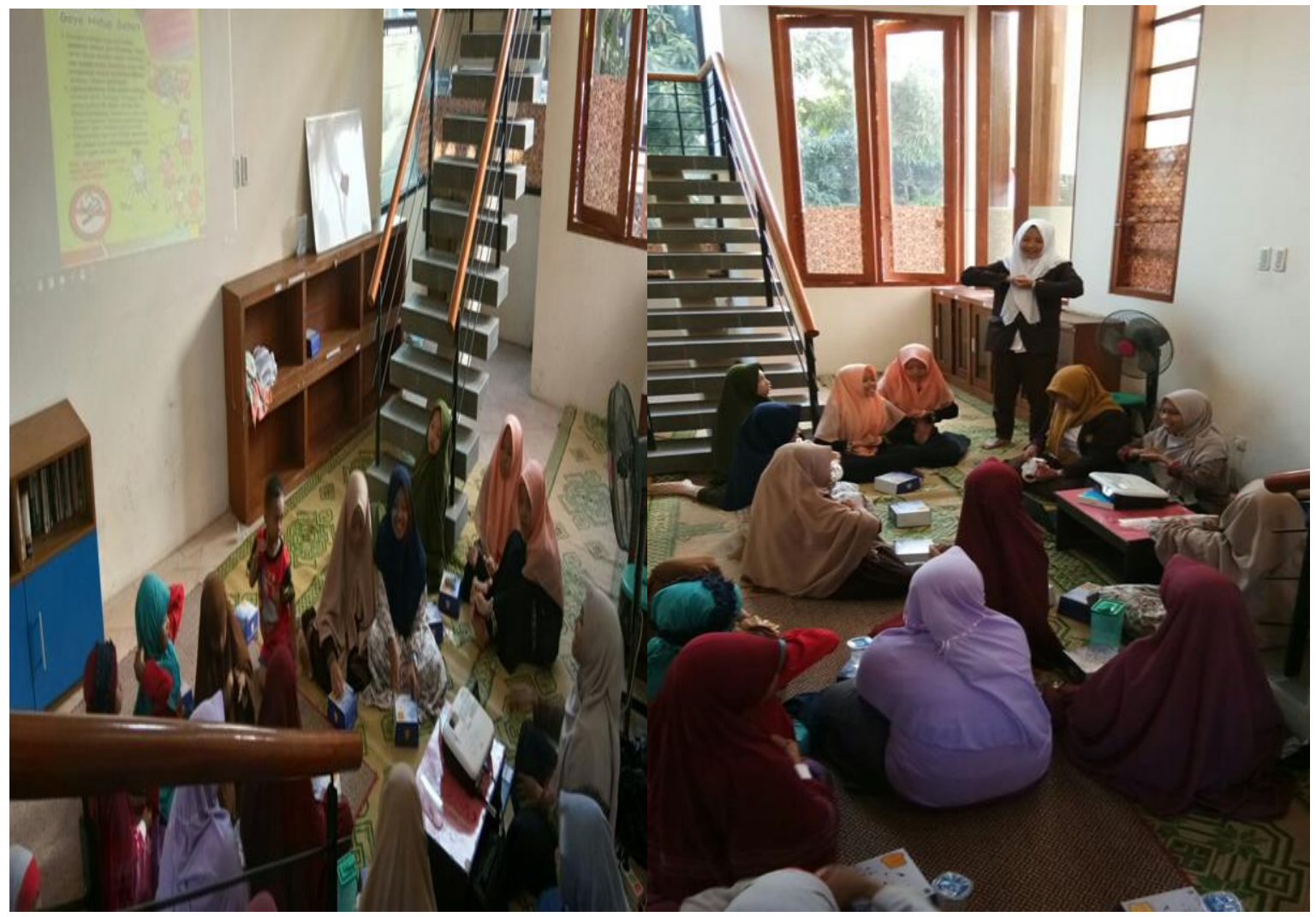

Gambar 3. Edukasi tentang PHBS dengan Media Audio Visual dan Demonstrasi Cuci Tangan

Gambar 3. Menunjukkan pelaksanaan edukasi PHBS yang dilakukan oleh dosen dan demonstrasi cuci tangan dilakukan oleh mahasiswa yang dilibatkan dalam kegiatan PPM ini. Setelah diberikan edukasi tentang PHBS pengetahuan dan keterampilan anak asuh di Panti Asuhan Yatim dan Dhuafa Wiwin Muslimah Yogyakarta meningkat hal ini ditunjukkan dengan semua anak asuh (100\%) mampu mendemonstrasikan ulang cuci tangan dengan benar dan mampu menjawab pertanyaan yang diberikan dengan benar.

Edukasi atau pemberian pendidikan kesehatan merupakan salah satu metode yang dapat dilakukan untuk merubah perilaku masyarakat. Edukasi merupakan upaya pembelajaran kepada masyarakat agar mau melakukan tindakan-tindakan untuk memelihara dan meningkatkan kesehatan. Perubahan perilaku dan peningkatan kesehatan yang dihasilkan oleh edukasi didasarkan kepada pengetahuan dan kesadaran melalui proses pembelajaran (Notoatmodjo, 2005).

Dukungan dan peran aktif pengurus panti asuhan dan anak asuh memberikan kemudahan dalam memaksimalkan pengetahuan dan perubahan perilaku di lingkungan Panti Asuhan Yatim dan Dhuafa Wiwin Muslimah Yogyakarta. Kegiatan edukasi dapat menjadi dasar dalam melakukan perilaku hidup bersih dan sehat yang dilakukan di panti asuhan. Untuk merubah perilaku masyarakat yang belum mencapai derajat kesehatan yang 
baik maka kegiatan edukasi harus terus dilakukan. Sarana prasarana menjadi salah satu faktor penghambat dari pelaksanaan kegiatan PHBS (Putri, 2017). Sarana prasarana yang menjadi penghambat pelaksanaan PHBS di Panti Asuhan Yatim dan Dhuafa Wiwin Muslimah Yogyakarta ini adalah masih adanya beberapa alat kebersihan diri yang digunakan secara bersama oleh anak asuh. Dalam kegiatan PPM ini juga memberikan alat bantu PHBS berupa paket kebersihan diri untuk setiap anak asuh yang terdiri dari keranjang alat mandi, sabun cari, pasta gigi, sampo, sikat gigi.

\section{Kesimpulan}

Hasil pemeriksaan kebersihan menunjukkan $89 \%$ anak asuh di Panti Asuhan Yatim dan Dhuafa Wiwin Muslimah mempunyai kutu rambut, 22\% telinga anak asuh dalam kondisi kotor, 50\% gigi anak asuh berlubang (karies), 44\% kuku tangan dan kaki panjang dan kotor. Dari hasil penyuluhan atau edukasi kepada 18 orang anak asuh yang hadir, semuanya mengatakan bisa memahami mengenai perilaku hidup bersih dan sehat. Hal tersebut dapat dilihat dari semua anak asuh (100\%) mampu mendemonstrasikan ulang cuci tangan secara benar dan mampu menjawab pertanyaan yang diajukan. Dukungan dan peran aktif semua pihak di dalam lingkungan panti asuhan dalam pelaksanaan PHBS menjadi salah satu faktor pendorong pelaksanaan PHBS. Keterbatasan sarana dan prasarana di panti asuhan menjadi salah satu factor penghambat pelaksanaan PHBS.

\section{Daftar Pustaka}

Andriansyah, Y \& Rahmantari, D, N. (2013). Penyuluhan dan Praktik PHBS dalam Mewujudkan Masyarakat Desa Pedulu Sehat. Jurnal Inovasi dan Kewirausahaan. Vol 2 (1). Hal 45-50

Departemen Kesehatan RI. (2005). Perilaku Hidup Bersih dan Sehat di Indonesia . Jakarta

Dermawan, D. (2012). Buku Ajar Keperawatan Komunitas. Yogyakarta : Gosyen Publishing

Kemenkes RI. (2011). Pedoman Pembinaan Perilaku Hidup Bersih dan Sehat (PHBS). Jakarta: Kementrian Kesehatan RI.

Kurniawan, H. (2017). Upaya Peningkatan Derajat Kesehatan pada Anak di Panti Asuhan Melalui Edukasi Perilaku Hidup Bersih dan Sehat. Jurnal Pengabdian Masyarakat Ipteks. Vol 3(1). Hal 9-16

Notoatmodjo, S. (2007). Promosi Kesehatan dan Ilmu Perilaku . Jakarta: Rineka Cipta.

Putri, M.A. (2017). Perilaku Hidup Bersih dan Sehat (PHBS) Anak di Panti Asuhan Al-Akbar Pekanbaru. JOM FISIP. Vol 4 (2). Hal 1-14 